\title{
Knowledge Management and Intellectual Capital Role in Achieving Creativity for Teaching Staff Members at Jordanian Universities
}

\author{
Ahmad Areiqat $^{1}$, May Ahmad ${ }^{2} \&$ Ahmad Alheet $^{3}$ \\ ${ }^{1}$ Associate Prof., Department of Business Management, Business School, Al-Ahliyya Amman University, Jordan \\ ${ }^{2}$ Lecturer, Department of Business Management, Business School, Al-Ahliyya Amman University, Jordan \\ ${ }^{3}$ Assistant Prof., Department of Business Management, Business School, Al-Ahliyya Amman University, Jordan \\ Correspondence: Ahmad Areiqat, Associate Prof., Department of Business Management, Business School, \\ Al-Ahliyya Amman University, Jordan. E-mail: ahmadareiqat@ammanu.edu.jo
}

Received: September 25, 2018

doi:10.5539/ijbm.v13n12p38

\author{
Accepted: October 20, $2018 \quad$ Online Published: November 12, 2018 \\ URL: https://doi.org/10.5539/ijbm.v13n12p38
}

\begin{abstract}
The aim of this research is to determine the role of intellectual capital in achieving creativity for teaching staff members at Jordanian universities. The problematic of the study stems from that the majority of the Jordanian universities don't give enough attention for the intellectual capital and its effect on creativity, The descriptive approach used to identify the role played by intellectual capital in achieving creativity in Jordanian universities operating in the Hashemite Kingdom of Jordan until 2017, The questionnaire was used to collect the necessary data from the sample, the study population consists of (30612) administrative and academic all working individuals (administrative and academic) in the Jordanian universities , a random / stratified sample was selected, the research comes out many results such as the percentage of faculty members who submitted less than five scientific publications in the field of their specialties amounted to $67.3 \%$, there is a statistically significant effect to the components of intellectual capital in the achievement of creativity among the faculty members in Jordanian universities operating in the Hashemite kingdom of Jordan, finally the research suggests some recommendation such as working in rising awareness and adopting the concept of intellectual capital because of its important role in developing creativity among faculty members in Jordanian universities and thus its reflection on the development of the Jordanian society.
\end{abstract}

Keywords: intellectual capital, human capital, creativity, developing countries, Jordan

\section{Introduction}

Knowledge, knowledge management and intellectual capital pose vital subjects, because of their accelerated high importance in the knowledge time that the whole world live, researchers and thinkers didn't realize that they are like phenomena that can be studied and processed as specialized administrative issues, where these subjects had only this scientific caring recently.

As such, caring of the kind of " Capital" represented by this knowledge is no longer a secret, and the concrete capital is no longer sufficient to use it in calculating assets value for any organization, where another intangible capital is summarized in knowledge, skills and important psychological aspects and relations for the success of any organization, specialists see that these features pose an important intellectual capital, and they benefit in achieving an accumulation in knowledge enough to innovate "Knowledge Management" as a subject and a modern specialized activity (Jaradat, Naser, Al-Muaani, \& Saleh, 2011; Al-Yaseen, Al-Jaghoub, Al-Shorbaji, \& Salim, 2010; Anas, Al-Soud, Al-Yaseen, \& Al-Jaghoub, 2014; Al-Yaseen, Eldabi, Paul, 2008; Al-Jaghoub, Al-Jedaya, \& Al-Yaseen, 2007).

Caring of knowledge management, especially under the great and big developments in all fields, has founded a new reality and new concepts that put decision makers and organizations against big challenges, this caring is also, in turn, applied on the intellectual capital which is found in the organization. It should be noted that the connection between knowledge management and intellectual capital is still un crystallized, however, the relationship between them is clear, the caring of the intellectual capital, until a recent time, was confined to manage the calculations that try to estimate, measure, develop it and monitor the investment inside it, where its common measurement was investing in training and teaching. But the behavioral sciences specialists have 
recently taken care of it through diagnosing some of teaching staff members features linked with their psychological situation, and they considered them like a psychological capital for the organization, and they began caring of the social dimension represented by the nature of the social relationships between teaching staff members themselves and external parties, and these relationships are very important, for they are reflected on the organization performance positively, if they are positive, and negatively if they are negative (Jaradat, Naser, Al-Muaani, \& Saleh, 2011; Eldabi, Paul, \& Sbeih, 2003; Al-Jaghoub, Al-yaseen, Hourani, Al-Haddadeh, \& Salim, 2009; Al-Yaseen, Al-Gweri, \& Al-Jaghoub, 2005; Al-Yaseen, 2012; Al-Yaseen, El-Haddadeh, Al-Jaghoub, \& Al-Gweri, 2007) thinkers have taken these relationships as a social capital, and confined to measure and invest it and monitor its effects on the organization performance.

Creativity is considered as one of the vital elements to achieve excellence and distinction in many of various fields, creativity concept is a wide one uneasily to be expressed only by words, and the creativity definition is different by the variance of the context in which it is used, in some institutions, creativity is associated with talent, and in other institutions is associated with talent and professionally, and many synonyms are accompanied with creativity concept, such as: talent, skill and innovation.

Hence, the researcher sought to take the creativity and intellectual capital to study the relationship between them, and to clarify the role played by the intellectual capital in achieving creativity at Jordanian Universities. In order to achieve these study goals, the researcher will seek to determine the components of the intellectual capital in details, which are consisted of structural capital, human capital, social capital and psychological capital, and get acquainted with the components and elements of creativity. Also, the study seeks to find out the reality of the Jordanian Universities and get acquainted with the used and usual mechanisms inside them to achieve creativity to manage the intellectual capital.

The importance of this study lies in that it will present a scientific subject to be added into this field for researchers, decision makers at Jordanian Universities and the teaching staff members inside them, for the studies about this subject are limited within the borders of the Hashemite Kingdom of Jordan, undoubtedly, the education institutions, which are considered as knowledge sources, are in a continuous need to keep up the development and increase investment approaches in the human resources to achieve advancement and to keep up the time requirements and labor market needs, otherwise, by passing of time, they will be retreated which leads to the weakness of its pioneer role in making generations proper for work and reduces their ability to adapt with the renewed reality in labor markets in all sectors.

\subsection{Study Questions}

The problematic of the study stems from that the majority of the Jordanian Universities don't give enough attention for the intellectual capital and its effect on creativity, and this what was shown by some studies that took the effect of the various components of the intellectual capital on creativity, also, the problematic of the study stems from lack of having a scientific knowledge about the Jordanian Universities, especially in explaining the contribution of the intellectual capital owned by those universities in achieving creativity for teaching staff members inside them.

So, the purpose of this study is: to study the role of intellectual capital in achieving creativity for teaching staff members at Jordanian Universities worked in the Hashemite Kingdom of Jordan, and the study purpose can be achieved through answering the following questions:

The first major question: what is the role of intellectual capital in achieving creativity for teaching staff at Jordanian Universities worked in the Hashemite Kingdom of Jordan. The first major question is ramified into the following sub-questions:

- What is the role of the structural capital in achieving creativity for teaching staff members at Jordanian Universities worked in the Hashemite Kingdom of Jordan?

- What is the role of the human capital in achieving creativity for teaching staff members at Jordanian Universities worked in the Hashemite Kingdom of Jordan?

- What is the role of the social capital in achieving creativity for teaching staff members at Jordanian Universities worked in the Hashemite Kingdom of Jordan?

- What is the role of the psychological capital in achieving creativity for teaching staff members at Jordanian Universities worked in the Hashemite Kingdom of Jordan?

The second major question: What is the nature of relationship between intellectual capital and developing the ability to be creative. 
The third major question: What are the creativity areas at Jordanian Universities, and how can we achieve them through using the available intellectual capital?

The fourth major question: Are there any differences among the Jordanian Universities in realizing the teaching staff members in those universities to the components of the intellectual capital due to demographic changes?

On the light of the problematic of the study, and related literature reviews, the researcher determined the variables that he will examine, as they are written in the following model:

\begin{tabular}{|ll|}
\hline \multicolumn{1}{|l|}{ Independent Variables } \\
\hline Components of Intellectual Capital \\
1- & Structural Capital \\
- & Systems \\
- & Patents \\
2- & Hutabase \\
- & Education \\
- & Training \\
- & Experience \\
- & Skill \\
3- & Components of Social Capital \\
- & Internal relationships among workers \\
- & External relationships \\
4- & Psychological Capital \\
- & Optimism \\
- & Trust \\
- & Hope \\
- & Resiliency \\
- & Emotional Balance \\
\hline
\end{tabular}

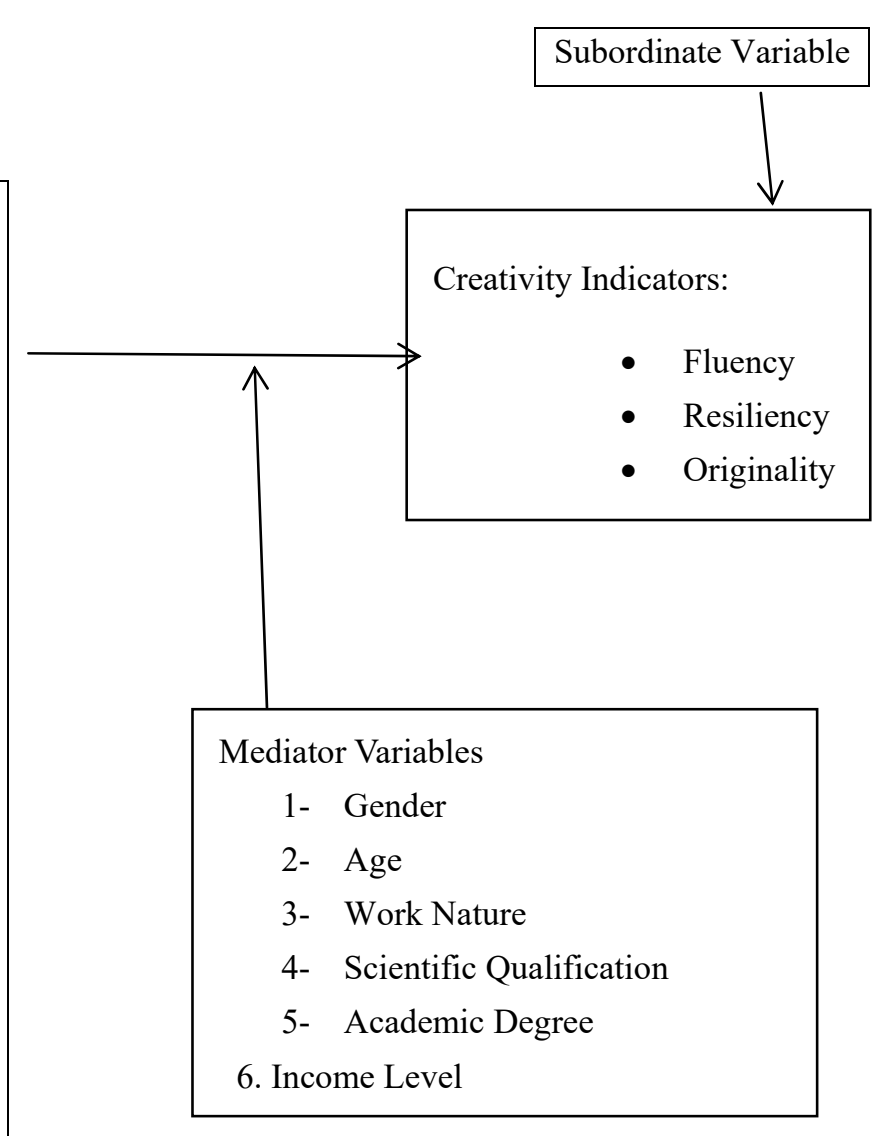

Figure 1. Research model

Source: Al-Zeer \& Emad (2016).

\subsection{Study Importance}

Scholars paid attention to the studying of the intellectual capital to determine its components and how to measure and develop it, for it is a modern subject, relatively, so it is expected that their results will help decision makers at Jordanian Universities to develop and improve the universities performance through developing creativity and intellectual concepts taking mechanism for the learners and, on the one hand, and for decision makers at universities on the other hand, especially concerning the practical and job side.

\subsection{Study Goals}

The main goal of this study is to determine the role played by the intellectual capital to achieve creativity for teaching staff members at Jordanian Universities in the Hashemite Kingdom of Jordan. 


\section{The sub goals are:}

- Determining the role of structural capital components (systems, patents and database) in achieving creativity for teaching staff members at Jordanian Universities in the Hashemite Kingdom of Jordan.

- Determining the role of human capital components (teaching, training, experience and skill) in achieving creativity for teaching staff members at Jordanian Universities in the Hashemite Kingdom of Jordan.

- Determining the role of social capital components (internal and external relations) in achieving creativity for teaching staff members in the Jordanian Universities in the Hashemite Kingdom of Jordan.

- Determining the role of psychological capital components (optimism, trust, hope, resiliency and emotional balance) in achieving creativity for teaching staff members at Jordanian Universities in the Hashemite Kingdom of Jordan.

\subsection{Definition of Study Terminology}

- Intellectual Capital: All knowledge owned by the organization and exploited to serve it (Fernandez, Irma, Gonzalea, \& Sabherwal, 2004), groups of idea, inventions, technologies, general knowledge, computer programs, designs, data skills, operations, creativity and applications in the organization, and it is every knowledge that can be transformed into profit, and it will be measured in this study through its components, they are: structural capital, human capital, social capital and psychological capital.

- Structural Capital: It poses the overt knowledge of the organizations, and it includes systems, patents, database, procedures, taught lessons, regulatory culture and others (Al-Jaghoub, Al-Yaseen, \& Al-Hourani, 2010; Al-Yaseen, Eldabi, Lees, \& Paul, 2006; Jaradat, Al-Muaani, \& Saleh, 2011). Structural capital is characterized that it represents all values which still found in the organization, even if the individuals leave the work, and it will be measured in this study through: systems, patents and database.

- Systems: A group of reactive elements with each other to achieve a certain goal.

- Patents: They are an exclusive right given for an invention that is productive or a process that gives a new approach to achieve a work, or gives a new technical solution for a problem, the patent guarantees to its owner the protection of their invention, and generally gives them a limited period for 20 years.

- Database: A group of logical data elements associated with each other with a mathematical relation saved in computer systematically, where a computer program called database engine, facilitates dealing with them, searching through these data and the possibility to add and adjust them.

- Human Capital: The accumulated sum of the experience, expertise, knowledge, creativity, energy and enthusiasm shown by the person to invest them in their works (Al-Muaani, Ahmad, Orayqaat, Ahamd, Al-Saleh, Asma'a, \& Naser, 2011; Al-Yaseen, Eldabi, \& Paul, 2004), for the purposes of this study, it will be measured through its components, they are: teaching, training, practical experience and skill.

- Education: It is one of the human capital components, and it will be measured through identifying the scientific qualification owned by teaching staff members at Jordanian Universities, and also through the academic degree of the teaching staff members in those universities.

- Training: It means the courses and trainings that the family members have, whether in their working inside or outside the university.

- Experience: It is a knowledge from an advanced type, the expert is a person who has a knowledge for performing tasks better than the others, for they have many levels of skills and knowledge (Fernandez, Irma, Gonzalea Avelino, \& Sabherwal, 2004).

- Skill : The features of the complicated activity that requires a period of intentional training, and systematic practice, where it is performed well.

- Social Capital: The relationships owned by the organization workers, and it allows them to participate and cooperate through mechanisms, such as (networks, mutual trust, criteria and values) to achieve a mutual interest (Ibarra, 1993; Al-Yaseen, Al-Gweri, \& Al-Jaghoub, 2007; Al-Yaseen, Al-Soud, \& Al-Jaghoub, 2015), and it will be measured in this study through: social relations among the teaching staff members at universities, and the external relations with the concerned parties.

- Internal Relations Among Family Members: It means the relationship of teaching staff at Jordanian Universities, and it may be a positive one in favor of the individual, or a negative one (conflict on positions, authority and decision) so it will be ferocious. 
- External Relations: They are the relationship between the university and the concerned external parties.

- Psychological Capital: The positive psychological development situation of the individual, and it is characterized by positive optimism about the possibility to succeed now and in the future, and the high confidence to take the necessary effort to succeed in the challenging tasks, hope that included the personal determination to go forward, and the resiliency when getting in troubles and hard situations, emotional balance with the family area and work (Jensen, \& Luthans, 2007; Al-Yaseen, Al-Soud, \& Al-Jaghoub, 2013; Al-Jaghoub, Al-Hourani, \& Al-Yaseen, 2009), and it will be measured in this study through measuring its components represented by: trust, optimism, hope, resiliency and emotional balance.

- Trust: The ability to exert the necessary effort to succeed in the challenging tasks (Jensen, \& Luthans, 2007).

- Optimism: Believing in the possibility of success now and in the future, and optimism interprets taking risk and accepting its results without affecting negatively the individual spirits or to make them feel disappointed [21].

- Hope: The personal determination to go forward and preserving the effort towards achieving goals, and the ability to see the alternatives for the possible operations to reach these goals, and redirecting the paths towards goals [21].

- Resiliency: The ability to successfully keep up the changes in the environment (Jensen, \& Luthans, 2007)..

- Emotional Balance: The situation of stability and emotional gratification that the individual lives with their area (family), and in their relationships with the others, workmates, friends and a family.

- Innovation: A process to innovate something and present it well and in a new way, and it is a change in things working way, renewing and giving an alternative (Al-Muaani, Ahmad, Orayqaat, Ahamd, Al-Saleh, Asma'a, \& Naser, 2011; Al-Yaseen, Hourani, \& Al-Jaghoub, 2012; Eldabi, Lees, \& Paul, 2006; Al-Yaseen, Al-Jaghoub, \& Al-Salhi, 2011), and it will be measured in this study through: energy, resiliency, originality and details.

The concepts of those changes were taken according to (Al-Tartouri, Mohamed \& Al-Qudah, Mohamed, 2007) as follows:

- Fluency: The ability to produce a big amount of creative ideas during certain time period.

- Resiliency: The ability to adapt with the changes and latest attitudes, and fast transition from a static angle to a freed one.

- Originality : Presenting ingenious outcomes that fit the goal and the job they work for, and rejecting the familiar and ready solutions, and taking a new behavior consistent with the aspired goal.

- Elaboration: The ability to give more elaborations or presenting new additions for a certain idea, where we get acquainted with the precise details and show them.

\subsection{Determinants and Limits of the Study}

This study will be limited to the Jordanian Universities worked in the Hashemite Kingdom of Jordan, for the purpose of studying the role of the intellectual capital in achieving creativity for teaching staff members at Jordanian Universities in the Hashemite Kingdom of Jordan, so the determinants of this study are:

- The outcomes of this study are only for Jordanian Universities worked in the Hashemite Kingdom of Jordan, and there is no way to generalize its outcome for the whole universities outside Jordan.

- Depending on study sample viewpoints in collecting data (researched)

\section{Previous Studies and Discussion}

The interplay of leadership, absorptive capacity, and organizational learning culture in open innovation: Testing a moderated mediation model This research aimed to develop a model to explain how leadership interacts with absorptive capacity and organizational learning culture to influence open innovation outcomes. The model is tested empirically using data sourced from managers working in diverse sectors in India. Results reveal that empowering leadership leads to enhanced open innovation outcomes through the intervention of organizational learning culture.

The purpose of this paper is to explore the relationship between intellectual capital (IC) and performance of public universities in emerging countries in order to identify patterns and provide recommendations that may turn the universities' IC into development opportunities, in terms of research, innovation, and education. 
The analysis targeted the whole population of the public universities in the Republic of Colombia. A cluster analysis, based on five performance variables, has been conducted. Then, the IC of the universities pertaining to the three resulting clusters has been compared. Subsequently, for each performance variable, the IC of above-average and below-average universities has been benchmarked.

The results of this study show how different aspects of IC are associated with University performance. Among the many, the authors found that universities should achieve a critical mass to obtain outstanding research and innovation results. The findings also identify the particular importance of both students and scholars' international mobility programs for most of the performance variables.

Since our research is dealing with IC and innovation the findings may help the researchers to focus on both students and scholars as two main parts in creating innovation through intellectual capital.

2)Transmitting competencies at universities in Kazakhstan: intellectual capital of teachers

The purpose of this paper is to measure individual intellectual capital (IC) of academic staff as well as to test its impact on the employability readiness of future graduates and the reduction of the discrepancy between competencies developed and grades obtained with the help of two indicators, i.e. intellectual capital indicator (ICI) and employability readiness indicator (ERI). While ICI measures the level of a teacher's competencies to be transmitted in the education process, ERI measures the level of a student's competencies developed after completing relevant courses.

This is an empirical research carried out in the form of a case study. Regression model is applied to find the influence of ICI on ERI. The minimization problem is set with relevant constraints to decrease the discrepancy between ERI and traditional grade point average (GPA).

The data were collected at one Kazakh university and from experts from academia and industry by means of documentary analysis, specialized tests and structured interviews. The direct impact of ICI on ERI is confirmed and the optimal level of ICI that permits an effective decrease in the discrepancy between ERI and GPA is identified.

This study will help researchers to prove that there is a relationship between intellectual capital of academic staff and grades obtained from students.

3) Academic spinoffs as a value driver for intellectual capital: the case of the University of Pisa

The purpose of this paper is to discuss academic spinoffs (ASO) as an expression of the value creation of university technology transfer (TT) investments. More recently, scholars have emphasized intellectual capital's (IC) importance, also for universities in obtaining competitive advantages and by creating value. Such spinoffs are key to regional development, as a primary aspect of universities' IC.

The authors tested the aim through a sample of the University of Pisa's spinoffs. The authors measured the value the university's third mission investment generates on the area by means of entrepreneurship through two different approaches. First, the authors defined a multiplier of the TT investment (university TT multiplier) and then explored the IC components' contributions to the ASOs' enterprise value (EV).

The results show that the University of Pisa's TT investments positively impact the local community through the spinoff system, both in economic terms and in IC. In the long term, these investments can enrich scientific humus and entrepreneurial mindsets.

This study relates to our research through emphasizing intellectual capital importance for universities to create competitive advantage which hopefully will be one of the results we aim to reach.

4) The impact of higher education on entrepreneurial intention and human capital

Author(s):

The purpose of this paper is to investigate the impact of higher education on the emergence of entrepreneurial intention (EI) and human capital (HC) as a component of intellectual capital (IC) that strongly influences the entrepreneurial process.

On the basis of a literature review, a theoretical model that is focused on the theory of planned behaviour was defined to verify the impact of higher education on the development of EI and HC. To this end, the structural equation modelling methodology was applied to two samples of students and academics, which differ each other in terms of both education level and specific characteristics of entrepreneurship education activities. 
The main results show that there are significant differences between the two considered samples. In particular, the level and specific characteristics of entrepreneurial education are the key factors for the development of EI and $\mathrm{HC}$.

The research may be of relevance for universities and policy makers. Universities must devote more attention to training and practice-oriented entrepreneurial courses and collateral activities (projects, initiatives, actions), both for students (first mission) and academic aspiring entrepreneurs (third mission) to encourage the emergence of EI and $\mathrm{HC}$ formation. For policy makers, this study suggests the need to define policy guidelines and frameworks to support universities' educational programmes and activities to strengthen the entrepreneurial process, so that they can be consistent with the EU and national entrepreneurship policies.

The first main hypothesis of the current study, therefore, there is a significant statistical effect of the components of intellectual capital in the achievement of creativity among the teaching stuff of the Jordanian universities operating in the Hashemite Kingdom of Jordan.

Also indicates that there is essential and major role for the intellectual capital in achieving creativity, and this answers the first main question of the current study.

The first question of the current study, where there is significant role to intellectual capital in achievement creativity among the faculty members. Also, it answers the second question of the current study, where the relationship between the intellectual capital and development of creativity ability is strong correlation relationship.

The third question of the current study, where the creativity could be developed in the universities by using the intellectual capital, such as improving the readiness of graduates to work. Also it contradicts the first main hypothesis of the current study, where there is a significant statistical effect of the components of intellectual capital in the achievement of creativity among the faculty members in Jordanian universities operating in the Hashemite Kingdom of Jordan.

The first main question of the current study, where is an important and vital role for the intellectual capital in achieving creativity among faculty members in Jordanian universities operating in the Hashemite Kingdom of Jordan.

Also it answers the third question of the current study, where, there are societal and pioneering areas for universities to lead innovation through exploiting the intellectual capital. But the results of (Mariana et al) study contradict the first main hypothesis of the current study, where the is a significant statistical effect to the components of intellectual capital in the achievement of creativity among the faculty members of Jordanian universities operating in the Hashemite Kingdom of Jordan.

While the second sub-question of the current study, where there is an impact to intellectual capital in achieving creativity among the faculty members in the Jordanian universities operating in the Hashemite Kingdom of Jordan. It also answers the third question of the current study in terms of that the pioneer leadership is one of the areas of creativity in Jordanian universities. But his study has contradicted with the second sub-hypothesis of the current study, where the current study found that there is a significant statistical effect to the components of intellectual capital (Teaching, Learning, Experience and Skill) in the achievement of creativity among the faculty members in Jordanian universities operating in Jordan.

\section{Methodology}

- Type of the study: The descriptive approach will be used to identify the role played by intellectual capital in achieving creativity in Jordanian universities operating in the Hashemite Kingdom of Jordan until 2017.

- Data collection methods: The questionnaire was used to collect the necessary data from the sample.

- The study population: The study population consists of (30612) administrative and academic all working individuals (administrative and academic) in the Jordanian universities (governmental and private) operating in the Hashemite Kingdom of Jordan until 2017. according to the statistical report issued by the Ministry of Higher Education and Scientific Research in 2018 for the academic year 2016-2017, academic and administrative staff, are classified as shown in Table (1): www.mohe.gov.jo 
Table 1. Distribution of workers in Jordanian universities by university, and nature of work

\begin{tabular}{clccc}
\hline$\#$ & University Name & Academic & Administrative & Total \\
\hline 1. & University of Jordan & 1567 & 3218 & 4785 \\
.2 & German Jordanian & 273 & 382 & 655 \\
.3 & Hashemite University & 675 & 953 & 1628 \\
.4 & Al-albayt & 371 & 931 & 1302 \\
.5 & Al-Balqa & 1560 & 3017 & 4667 \\
6. & Hussein bin Talal & 331 & 855 & 1216 \\
7. & Tafila Technical & 237 & 678 \\
8. & Science and Technology & 913 & 3070 \\
9. & Yarmouk University & 1082 & 2157 & 2632 \\
10. & Muta & 602 & 1550 & 2014 \\
11. & Islamic sciences & 394 & 1412 & 644 \\
12. & America - Madaba & 74 & 250 & 188 \\
13. & Irbid al ahliyya & 90 & 114 & 632 \\
14. & Al Isra & 210 & 188 & 298 \\
15. & Sumaya for Technology & 124 & 687 \\
16. & Petra & 288 & 422 & 635 \\
17. & al zarqa & 319 & 174 & 899 \\
18. & Al Zaytoneh & 311 & 399 & 350 \\
19 & Middle east & 173 & 316 & 318 \\
20. & Jadara & 140 & 588 & 841 \\
21. & applied Sciences & 265 & 356 \\
22. & Jerash & 172 & 177 & 562 \\
23. & Al ahliyya amman & 266 & 178 \\
24. & Ajloun & 70 & 178 & 285 \\
25. & Amman arab university & 138 & 1876 \\
26. & Philadelphia & 305 & 296 & \\
& Total & & 108 & 309 \\
\hline
\end{tabular}

\subsection{The Study Sample}

For the purposes of this study, a random / stratified sample was selected. The sample size as shown in Table 2 .

Table 2. Distribution of the sample of the study by university, and the nature of the work

\begin{tabular}{lllll}
\hline$\#$ & University Name & Academic & Administrative & Total \\
\hline .1 & Petra & 20 & 8 & 28 \\
.2 & al zarqa & 13 & 12 & 25 \\
.3 & Al Zaytoneh & 12 & 9 & 21 \\
.4 & Middle east & 52 & 29 & 81 \\
.5 & Jadara & 36 & 26 & 62 \\
.6 & applied Sciences & 63 & 36 & 99 \\
.7 & Jerash & 21 & 16 & 37 \\
.8 & Al ahliyya amman & 9 & 7 & 16 \\
.9 & Ajloun & 9 & 7 & 16 \\
& Total & 235 & 150 & 385 \\
\hline
\end{tabular}

According to the study problematic and its different elements, these hypotheses are presented:

The first major hypothesis: There is no effect with a statistical significance for the components of the intellectual capital to achieve creativity for teaching staff members at Jordanian Universities worked in the Hashemite Kingdom of Jordan. 
Sub-Hypotheses:

(1) There is no effect with a statistical significance for the components of the structural capital (systems, patents and database) to achieve creativity for teaching staff members at Jordanian Universities worked in the Hashemite Kingdom of Jordan.

(2) There is no effect with a statistical significance for the components of the human capital (teaching, training, experience and skill) to achieve creativity for teaching staff members at Jordanian Universities worked in the Hashemite Kingdom of Jordan.

(3) There is no effect with a statistical significance for the components of the social capital (internal and external relationships) to achieve creativity for teaching staff members at Jordanian Universities worked in the Hashemite Kingdom of Jordan.

(4) There is no effect with a statistical significance for the components of the psychological capital (optimism, trust, hope, resiliency and emotional balance) to achieve creativity for teaching staff members at Jordanian Universities worked in the Hashemite Kingdom of Jordan.

The second major hypothesis: There is no effect with a statistical significance for the features of the teaching staff members at Jordanian Universities worked in the Hashemite Kingdom of Jordan in terms of (gender, age, work nature, scientific qualification, academic degree and income level) to achieve creativity.

Sub-Hypotheses:

(1) There is no effect with a statistical significance of the gender variable to achieve creativity for teaching staff members at Jordanian Universities worked in the Hashemite Kingdom of Jordan.

(2) There is no effect with a statistical significance of the age variable to achieve creativity for teaching staff members at Jordanian Universities worked in the Hashemite Kingdom of Jordan.

(3) There is no effect with a statistical significance of the work nature variable to achieve creativity for teaching staff members at Jordanian Universities worked in the Hashemite Kingdom of Jordan.

(4) There is no effect with a statistical significance of the scientific qualification variable to achieve creativity for teaching staff members at Jordanian Universities worked in the Hashemite Kingdom of Jordan.

(5) There is no effect with a statistical significance of the academic degree variable to achieve creativity for teaching staff members at Jordanian Universities worked in the Hashemite Kingdom of Jordan.

(6) There is no effect with a statistical significance of the income level variable to achieve creativity for teaching staff members at Jordanian Universities worked in the Hashemite Kingdom of Jordan.

\section{Results}

1-Results for the Sample

The percentage of faculty members who submitted less than five scientific publications in the field of their specialties amounted to $67.3 \%$. while the percentage of those who submitted 5-10 scientific publications amounted to $15.6 \%$, and the percentage of those who submitted 11-20 Scientific publications amounted to $8.8 \%$. while the percentage of those who submitted more than 20 scientific publications amounted to $7.6 \%$.

2- Results Related to Intellectual Capital

The results showed that the intellectual capital has the greatest importance is Jordanian universities especially in the field of psychological capital as component of intellectual capital and then followed in terms of importance by the human capital, then social capital and finally structural capital. The results showed that the total average of intellectual capital reached to $3.86 \%$ with standard deviation of $0.65 \%$, and this result is consistent with a lot of previous studies that have indicated the importance of intellectual capital.

- Structural Capital: The results have Confirmed that the structural capital highly contributed in intellectual capital in an average of 3.54 and standard deviation of 0.76 .

The researchers of this research believe that systems and software are from the most important areas of the university's intellectual capital besides the systems and instructions in addition to the procedures and policies manual.

The results did not show a great importance for strategic and operational plans within the intellectual capital, but there is a strategic plan in the university, however, the participation of staff in the formulation of the strategic plan and operational plan is low. The researchers believe that this result is logical in view of the way that plans are formulated in the Jordanian universities, which are built on the basis of the spending items and not goals. 
Which calls for attention to the participation of all levels of management in the preparation of plans.

- Results Related to Human Capital:

Human capital took the second rank after the psychological capital in its contribution in development of intellectual capital with an arithmetic average of 3.56 and standard deviation of 0.66 . the field of learning and teaching took the first rank among human capital fields, followed by experience that contributes to providing human capital with appropriate cadres. The high importance of learning and education had been justified by accepting change and development in the nature of the work of university staff.

- Results related to psychological capital: where it occupied the first rank in terms of contribution in the development of intellectual capital in the Jordanian universes in average of 4.15 and standard deviation of 0.054 , where the results showed that emotional balance plays the most important role in psychological capital with an a mean average of 4.5 , while the optimism of workers is less important than the other areas.

Results related to social capital: where it took the third rank after the psychological capital in the development of the intellectual capital in Jordanian universities with an mean average of 3.55 and standard deviation of 0.78 , where the results showed that the internal relationships among the workers increase the social capital while the external relationships between the workers and the external parties of the university has low importance to the workers.

3-Results related to creativity and its indicators

The results showed that the creativity indicators were high with an mean average of 4 and standard deviation of 0.49 , and they showed a high importance of originality within creativity through the ability to the alternatives development to deal with problems. The researchers attribute the high results that related to creativity indicators to the changeable nature of working environment of Jordanian universities, which imposes on them the flexibility of responding to the environmental changes.

Summary of Results:

1) The intellectual capital represented by its areas (psychological capital and human capital) has a great importance in Jordanian universities.

2) The psychological capital explains a percentage of $57.2 \%$ of the variation in the indicators of creativity among workers is Jordanian Universities.

3) The human capital has a great role in the development of intellectual capital in Jordanian Universities (it comes in the second rank after the psychological capital).

4) There is a significant statistical effect at the level of significance $\alpha \leq 0.05$ to the demographic variables (sex, age, education level, job title, income level, the university) in the degree of employee's cognition of the components of intellectual capital in Jordanian Universities.

5) There is a significant statistical effect at the level of significance $\alpha \leq 0.05$ to the demographic variables (sex, age, education level, job title, income level, the university) in the degree of availability of indicators of creativity among faculty members in Jordanian Universities

6) There is a statistically significant effect to the components of intellectual capital in the achievement of creativity among the faculty members in Jordanian universities operating in the Hashemite Kingdom of Jordan.

7) There is a statistically significant effect to the components of human capital in the achievement of creativity among the faculty members in Jordanian universities operating in the Hashemite Kingdom of Jordan.

8) There is a correlation relationship between the intellectual capital and developing the ability for creativity.

9) From the creativity areas in the Jordanian universities that depend basically on intellectual capital: improving the readiness of graduates to work.

10) There is an important role to the intellectual capital on the society in developing entrepreneurship.

\section{Recommendations}

1) Working in rising awareness and adopting the concept of intellectual capital because of its important role in developing creativity among faculty members in Jordanian universities and thus its reflection on the development of the Jordanian society.

2) Focusing on entrepreneurship in Jordanian universities as one of important areas of creativity. 
3) Working to raise the graduate's efficiency and their readiness to work because of its importance in getting work opportunities and reducing the unemployment rates.

4) Raising the efficiency of the intellectual capital in the Jordanian universities because of its important role in achieving creativity in Jordanian universities.

5) Adopting the idea of incubators of creativity in civil society institutions, following traditional business incubators.

\section{References}

Al-Jaghoub, S., Al-Hourani, M., \& Al-Yaseen, H. (2009). Awareness and acceptability evaluation of using e-government services in developing countries: The case of Jordan. The Proceedings of the 3rd European Conference on Information Management and Evaluation, Gothenburg, Sweden.

Al-Jaghoub, S., Al-Jedaya, M., \& Al-Yaseen, H. (2007). Going Online? The Case of an E-Pharmacy in Jordan.

Al-Jaghoub, S., Al-Yaseen, H., \& Al-Hourani, M. (2010). Evaluation of awareness and acceptability of using e-government services in developing countries: The case of Jordan. The Electronic Journal Information Systems Evaluation (EJISE), 13(1).

Al-Jaghoub, S., Al-yaseen, H., Hourani, M., Al-Haddadeh, R., \& Salim, M. (2009). E-learning adoption in higher education in Jordon: vision, reality and change. European and Mediterranean Conference on Information Systems (EMCIS), Izmir, Turkey.

Al-Muaani, A., Orayqaat, A., Al-Saleh, A., \& Jradat, N. (2011). Contemporary Administrative Issues (1st ed.). Amman, Dar Wa'el for publishing.

Al-Tartouri, M., \& Al-Qudah, M. (2007). Educational Psychology Basics: Theory and Practice. Amman: Dar Al-Hamid for publishing and distribution.

Al-Yaseen H., Eldabi T., Paul, R. J., \& El-Haddadeh, R. (2008). Post- implementation evaluation of IT systems: A close review of politics. In: Irani Z and Love PED (Eds.), Evaluating Information Systems: Public and Private Sector (1st ed.). London: Butterworth Heinemann.

Al-Yaseen, H. M. (2012). Challenges of Implementing Health Care Information Systems in Developing Countries: Using a Mixed Method Research. Journal of Emerging Trends in Computing and Information Sciences, 3(11), 1521-1525.

Al-Yaseen, H., Al-Gweri, A., \& Al-Jaghoub, S. (2005). IS/IT investment appraisals: prior-implementation and post-implementation evaluation: the gap in the systems' costs.

Al-Yaseen, H., Al-Gweri, A., \& Al-Jaghoub, S. (2007). IS/IT Investment Appraisal: Prior and Post Implementation Evaluation in Jordanian Firms, International Conference Applied Computing (IADIS), Spain.

Al-Yaseen, H., Al-Jaghoub, S., \& Al-Salhi, N. (2011). Issues and Challenges in Implementing E-Learning Projects in Higher Education: The Case of Jordan. Proceedings of the 10th European Conference on E-Learning (ECEL), UK.

Al-Yaseen, H., Al-Jaghoub, S., Al-Shorbaji, M., \& Salim, M. (2010). Post-Implementation Evaluation of HealthCare Information Systems in Developing Countries. The Electronic Journal Information Systems Evaluation (EJISE), 13(1).

Al-Yaseen, H., Al-Soud, A., \& Al-Jaghoub, S. (2013). Assessing Jordan's e-government maturity level: Citizen's perspective on awareness, acceptability and usage of e-government services. International Journal of Electronic Government Research (IJEGR), 9(4).

Al-Yaseen, H., Al-Soud, A., \& Al-Jaghoub, S. (2015). Assessing Jordan's e-government maturity level: Citizen's perspective on awareness, acceptability and usage of e-government services.

Al-Yaseen, H., Eldabi, T., \& Paul, R. (2004). A quantitative assessment of operational use evaluation of information technology: benefits and barriers. Proceedings of the Tenth Americas Conference on Information Systems (AMCIS), New York, USA.

Al-Yaseen, H., Eldabi, T., Lees, D., \& Paul, R. (2006). Empirical post implementation evaluation of IT investment appraisals: Prior operational use and operational use. European Journal of Operational Research (EJOR), 173(3).

Al-Yaseen, H., Eldabi, T., Lees, D., \& Paul, R. (2006). Operational Use evaluation of IT investments: An 
investigation into potential benefits. European Journal of Operational Research (EJOR), 173(3).

Al-Yaseen, H., Eldabi, T., Paul, R., \& El-Haddadeh, R. (2008). Post-implementation evaluation of IT systems: A close review of practice. In Irani, Z. \& Love, P. E. D. (Eds.), Evaluating Information Systems: Public and Private Sector. Butterworth-Heinemann, Burlington.

Al-Yaseen, H., El-Haddadeh, R., Al-Jaghoub, S., \& Al-Gweri, A. (2007). The Adoption of POUE and OUE of IT Investments in the Jordanian Business Environment.

Al-Yaseen, H., Hourani, M., \& Al-Jaghoub, S. (2012). Success and Failure of eLearning Projects: Alignment of Vision and Reality, Change and Culture. Journal of Emerging Trends in Computing and Information Sciences (JEiTcis), 3(2).

Al-Zeer, E. (2016). Unpublished Phd Thesis, entitled : The Role Of Intellectual Capital In Achieving Creativity For Workers Of the Palestinian Universities Worked In West Bank. University of Palestine- Hebron/ Palestine .

Anas, R., Al-Soud, H., Al-Yaseen, S., \& Al-Jaghoub, H. (2014). Jordan's e-Government at the crossroads. Transforming Government: People, Process and Policy (TG:PPP), 8(4).

Daft R., L. (2001). Organization theory design (7th ed.), south western, Ohio.

Eldabi, T., Paul, R., \& Sbeih, H. (2003). Operational Use Evaluation / Post Implementation Evaluation of IT. United Kingdom Academy of Information Systems (UKAIS), 2003, Warwick, UK.

Fernandez, I., Gonzalea, A., \& Sabherwal, R. (2004). Knowledge Management: Challenges, Solutions, \& Technologies. Upper Saddle River, New Jersey: Pearson Education.

Ibarra, H. (1993). Network centrality, power \& Innovation: Involvement.

Jaradat, N., Al-Muaani, A., \& Saleh, A. (2011). Knowledge Management, Amman: Ithra'a for publishing and distribution.

Jensen, S. M., \& Luthans, F. (2007). Relationship Between Entrepreneurs Psychological Capital and their Authentic Leadership. Journal of Management, 18(2), 254-2773.

\section{Copyrights}

Copyright for this article is retained by the author(s), with first publication rights granted to the journal.

This is an open-access article distributed under the terms and conditions of the Creative Commons Attribution license (http://creativecommons.org/licenses/by/4.0/). 